\title{
An Analysis of the Emergency Ambulance Workload in the British Eastern Sovereign Base Area of Cyprus May 1995 to April 1998
}

Jonathan Leach, Angus Menzies

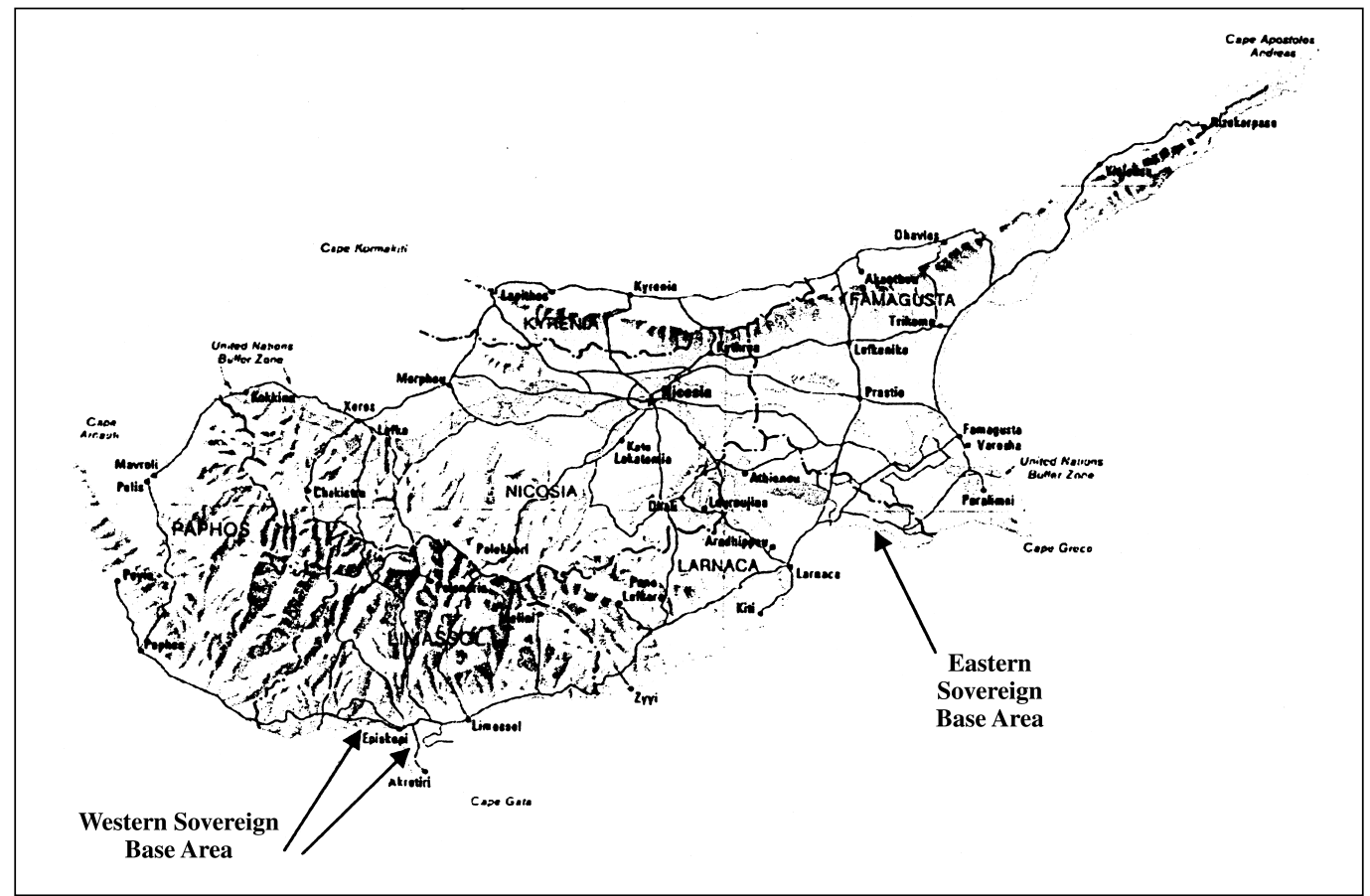

Fig 1. The Island of Cyprus showing the location of the two UK Sovereign Base Areas.

\section{ABSTRACT Objective}

To assess emergency ambulance workload in terms of patients treated, casemix and whether or not a member of the British Forces Community, between May 1995 and April 1998 within the British Eastern Sovereign Base area in Cyprus.

\section{Methods}

Retrospective analysis of all incidents attended within the study period.

\section{Results}

Lt Col Jonathan Leach RAMC

Senior Medical Officer Email:

leachaj@yahoo.com

Lt Col Angus Menzies RAMC

Deputy Senior Medical Officer

Medical Reception Station, Dhekelia, British Forces Post office 58
A total of 452 patients were treated of which $47 \%$ were members of the British Forces Community in Cyprus. 14 Deaths were attended of which 9 were due to road traffic accidents. Of all incidents attended $45 \%$ were following a road traffic accident and over three quarters of all patients treated had suffered trauma to some degree.

\section{Conclusion}

The British military ambulance and supporting medical services located in the Eastern Sovereign Base Area in Cyprus provide a service to the British
Forces Community, but the majority of patients treated are primarily the local Greek Cypriots with a sizeable minority of visiting tourists. Comment is made on the high incidence of morbidity and mortality from road traffic accidents within Cyprus as a whole.

\section{Keywords}

Road Traffic Accidents, Cyprus, Military Medicine, Mortality

\section{Introduction}

The Medical Reception Station Dhekelia is a military practice located in the Eastern Sovereign Base Area of Cyprus. Whilst its prime role is to assess and treat British Forces personnel, their families and other entitled personnel, for many years it has supplied an emergency ambulance service in support of the Civil Authorities. This workload, whilst providing an opportunity for the personnel to keep skilled in many aspects of emergency medicine that would be required on military operations, is not insignificant. The aim of this paper is to discuss the Dhekelia Emergency Ambulance Service work over the period May 1995 to April 1998 outlining the 
numbers and types of patients treated in relationship to the Republic of Cyprus and Her Majesty's Forces worldwide.

\section{Background}

As part of the independence agreement of 1960, the United Kingdom kept two main Sovereign Bases Areas and a number of other retained sites in Cyprus. The Eastern Sovereign Base Area covers an area of approximately 50.5 square miles and is situated approximately 10 miles east of the town of Larnaca and about 60 miles from the other Sovereign Base Area of Episkopi and Akrotiri on the island of Cyprus (See Figure 1). Within the Eastern Sovereign Base Area are three small enclaves of the Cypriot Republic - Dhekelia, Ormidihia, Xylotymbou villages and the Dhekelia Power Station. Additional population of The Eastern Sovereign Base area is made up of Service personnel, the civilian component and their families in Dhekelia and Ayios Nikolaos and the local Cypriots within the villages of Akhna Forest and Vrysoulles. To the north of the Sovereign Base Area are the Turkish controlled areas of Cyprus.

Within the Eastern Sovereign Base Area is the main road that runs from the eastern end of the island into the main part of the Republic of Cyprus. In particular it is the main thoroughfare for traffic from the largest tourist resorts in Cyprus namely Agia Napa and Protaris. During the period of the study, the road consisted of a single carriageway with many turnings and farm tracks on either side. During the latter part of 1999 (after the study period) it was replaced by a modern dual carriageway. The old road, which is still in use, is twisty and undulating - thus there are many blind spots for the unwary. Frequently, traffic, including farm vehicles, turned on or off the road with relatively little notice either onto or off the surrounding farmland or the coastal strip of sand and dunes. As a consequence of the nature of the road and the high road traffic accident rate in Cyprus a major part of the work on the Dhekelia Emergency Ambulance Service consists of treating casualties following road traffic accidents.

The Medical Reception Station (MRS) Dhekelia is located within part of the old British Military Hospital Dhekelia, which closed as a hospital in the 1970's. The MRS in many ways could be likened to a small community hospital in the UK. Skills and disciplines available include general practitioner, community midwifery, practice nurse, minor injuries unit including X Ray, physiotherapy, pharmacy, community psychiatric nursing, health visiting and speech and language therapy. In addition there is a 14 bed ward which is used for patients with minor illnesses or injuries. It is staffed mainly by military personnel who provide a 24 hour service in the acute disciplines. Explicitly seriously ill patients are transferred to hospital, whether this be The Princess Mary Hospital (TPMH), a British Forces Hospital, based in Akrotiri, approximately ninety minutes away by ambulance or to the civilian hospital in Larnaca which is 25 minutes from Dhekelia.

The MRS provides an emergency and routine ambulance service within the Sovereign Base. The more routine work consists of transferring patients to hospital, for example a soldier requiring an operation for a fractured ankle or if necessary taking a patient home following a consultation. The emergency "blue light" service is provided to Dhekelia Garrison and the surrounding area including the Greek village enclaves. A routine ambulance for the enclaves is provided by the Cypriot authorities. Staffing of the MRS ambulance consists of a locally employed driver, a paramedic (military Combat Medical Technician or Regimental Medical Assistant Class 1) and an "Assistant Medic". This "Assistant Medic" may be a Combat Medical Technician although it is more likely to be a member of one of the Professions Allied to Medicine such as a Pharmacy Technician (military) who has undergone further specialised training in life support. The emergency ambulance is supported by the duty/emergency doctor who is readily available for the more serious cases in a manner similar to a BASICS doctor in the United Kingdom. Base support in terms of communications between the medical services and other agencies is performed by the duty nurse on the MRS ward by the use of a radio and mobile telephone. The ambulance crew have the ability to establish and maintain an airway, use a defibrillator and start intravenous fluids. In addition there is a large amount of equipment suitable for stabilising and treating fractures. The emergency doctor's car has an almost identical set of equipment to the ambulance except that a larger and broader range of intravenous drugs is available. These drugs are those recommended for use in immediate care in the United Kingdom. They are kept within a locked refrigerator (with maximum and minimum thermometer) in the boot of a four wheel drive vehicle. The vehicle carries an additional defibrillator.

In other locations it has been relatively normal practice for the military medical services to provide emergency cover on the military base but none provides a service to the local civilian population. For example in the United Kingdom or in Germany the local civilian ambulance brigade provides the emergency ambulance service. Thus the requirement for the military medical 
services in Cyprus to provide an emergency ambulance service to the surrounding area is exceptional.

\section{Methods}

The records of the duty ambulance staff for all call outs between 1 May 1995 and 30 April 1998 were examined. A structured information sheet had been used for many years - this gave the date and time of the incident, its type, the number of patients involved and their ultimate disposal, whether this be to the patient's home, to the MRS or to the hospital. There was space for the name of the patient and their address, but in some cases (mainly either due to the illness of the patient or because of language problems) none was given. Using the name and address given it was possible to ascertain whether the patient was a member of the British Military Community in Cyprus. The records were coded and then analysed using Epi Info version 6 statistical program (Centers for Disease Surveillance). Further analysis was undertaken using Microsoft Excel version 97 spreadsheet. Excluded from the data was the workload of the ambulance for less urgent matters, whether this be transferring a patient to hospital or its use to provide medical cover for sporting or other events. Also excluded were training exercises, as were its use within Dhekelia Garrison as a routine method of transportation for patients.

Table 1. Total number of patients treated from 1 May 1995 until 30 Apr 1998

\begin{tabular}{llll}
\hline Year & $\begin{array}{l}\text { Total Patients } \\
\text { Treated }\end{array}$ & $\begin{array}{l}\text { Number not } \\
\text { members of } \\
\text { British Forces } \\
\text { Community }\end{array}$ & $\begin{array}{l}\text { \% not members } \\
\text { of British Forces } \\
\text { Community }\end{array}$ \\
\hline $1995-96$ & 168 & 96 & 57 \\
$1996-97$ & 166 & 86 & 52 \\
$1997-98$ & 118 & 56 & 47 \\
Totals & $\mathbf{4 5 2}$ & $\mathbf{2 3 8}$ & $\mathbf{5 2}$ \\
\hline
\end{tabular}

Table 2. Road Traffic Accidents attended 1 May 1995 to 30 April 98

\begin{tabular}{lllll}
\hline & $\begin{array}{l}\text { Total } \\
\text { incidents }\end{array}$ & $\begin{array}{l}\text { \% RTA } \\
\text { of total }\end{array}$ & $\begin{array}{l}\text { Certified } \\
\text { Dead }\end{array}$ & $\begin{array}{l}\text { Not } \\
\text { recorded }\end{array}$ \\
\hline Road Traffic Accident & 174 & 45 & 9 & 1 \\
$\begin{array}{l}\text { Non Road Traffic } \\
\text { Accident }\end{array}$ & 219 & 55 & 5 & 1 \\
Totals & $\mathbf{3 9 3}$ & $\mathbf{1 0 0}$ & $\mathbf{1 4}$ & $\mathbf{2}$ \\
\hline
\end{tabular}

\section{Results}

Table 1 gives the numbers of patients treated by the emergency ambulance from 1 May 1995 until 31 April 1998. Four hundred and fifty two patients were treated of which $47 \%$ were members of the British Forces Community. The nationality of those not normally entitled to routine treatment was not given, however the majority appeared to be Greek Cypriots (from their name and address) with a number of British, Israeli, Russian or Polish tourists.

Forty five percent of emergency ambulance call outs were for road traffic accidents (RTAs). A road traffic accident was defined as "involving personal injury occurring on the public highway (including footways) in which a road vehicle or pedestrian is involved"(1). Table 2 gives the number of RTAs attended over the study period plus the number of deaths. All the deaths due to RTAs were as a consequence of multiple injuries. Non-RTA deaths were following heart atacks (three), an overdose (one) and a drowning (one). A separate analysis of the emergency doctor workload shows that attendance at one incident per week is the average. This is in addition to the responsibilities as the duty general practitioner to the Garrison.

The number of call outs for May 95 to May 96, May 96 to May 97 and May 97 to May 98 were 146, 142 and 105 respectively. Thus on average the ambulance was called to an emergency every 2.7 days. The number of incidents attended was different from the number of patients treated as on many occasions more than one patient was involved. This was particularly the case for the RTAs.

A breakdown of the types of incidents shows that the vast majority of ambulance call outs were for trauma. Many of the minor trauma incidents involved military personnel either at work or undertaking adventure training. On coding whether an incident consisted of major or minor trauma a subjective judgement has been made as a formal trauma scoring system was not used at any stage. Similarly information that would allow for a trauma score to be generated from the receiving hospital is not available. Examples of significant trauma involving the chest, a fractured femur, fractured skull or multiple fractures have been assessed as major trauma whereas a fractured forearm or lower leg, minor trauma. Table 3 gives the casemix of the patients seen. $76.2 \%$ of all cases involved trauma.

Table 3. Casemix of patients seen by the Dhekelia Emergency Ambulance Service from 1 May 95 - 30 Apr 98

\begin{tabular}{lllllll}
\hline \multicolumn{2}{c}{$\begin{array}{l}\text { Major } \\
\text { Trauma }\end{array}$} & $\begin{array}{l}\text { Minor } \\
\text { Trauma }\end{array}$ & $\begin{array}{l}\text { Cardio- } \\
\text { vascular }\end{array}$ & Respiratory & $\begin{array}{l}\text { Nervous } \\
\text { incl } \\
\text { Psychiatric }\end{array}$ & Others \\
\hline $1995-96$ & 12 & 112 & 6 & 5 & 10 & 26 \\
$1996-97$ & 19 & 111 & 7 & 4 & 7 & 18 \\
$1997-98$ & 14 & 76 & 2 & 3 & 11 & 9 \\
Totals & $\mathbf{4 5}$ & $\mathbf{2 9 9}$ & $\mathbf{1 5}$ & $\mathbf{1 2}$ & $\mathbf{2 8}$ & $\mathbf{5 3}$ \\
Percent & 10.0 & 66.2 & 3.3 & 2.7 & 6.2 & 11.7 \\
\hline
\end{tabular}

For British Forces Personnel the policy was to assess and treat the patient initially at the MRS and then if necessary transfer the patient to the British Forces Hospital - The Princess Mary Hospital in Akrotiri. Only if the patient were in extreme danger was Larnaca used. Larnaca is the most accessible hospital with the range of specialities normally found in a small District General Hospital in the United Kingdom. For non-Forces personnel, almost all were taken to Larnaca unless the 
Table 4. Disposal of Patients

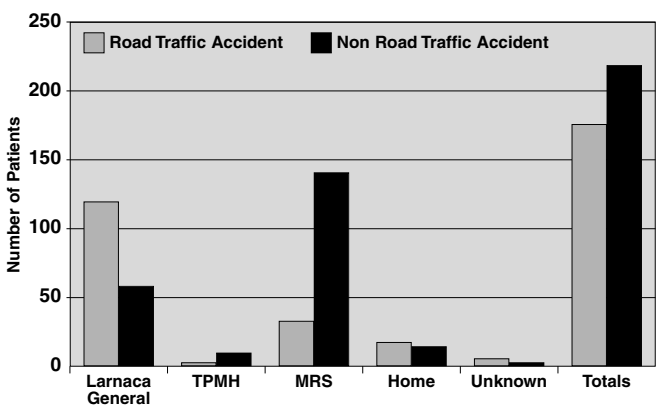

patient was judged as fit to go directly home or they were able to make their own arrangements to be seen by a doctor. Table 4 gives the disposal of patients over the study period.

\section{Discussion}

This study has shown that an incident involving trauma is the most likely activity of the Dhekelia Ambulance Service. Whilst the majority are not serious, a minority of cases involve significant injuries. For Service personnel, minor trauma due to training, sporting activities or adventure training are the most likely. The number of trauma incidents is considerably greater when compared with a UK civilian ambulance services, whereas the Dhekelia service does not generally see the medical conditions of the elderly or chronically ill.

Cyprus has one of the highest Road Traffic Accident rates when compared with the countries of the European Union. In 1996 the numbers of newly registered vehicles increased by $0.8 \%$ to 34,768 . The total number of vehicles on the register of the Department of Road Transport at the end of 1996 totalled 457,693 of which 249,301 were private saloon cars. The number of road accidents reported to the police decreased to 6,640 in 1996 compared with 7,138 in 1995. Human casualties in road accidents were 128 persons killed and 4,516 persons injured in 1996 as against 118 dead and 4,519 injured in 1995 . Of the 128 dead, 70 were drivers or passengers of motor cars, 32 were motor cyclists, 21 were pedestrians and 5 riders of bicycles(2). Comparison with the published statistics from the Greek mainland shows that drivers in Cyprus are twice as likely to have an accident although they are less likely to die(3). At the end of 1996 the number of licensed vehicles in Great Britain reached an all time high of 26.3 million. Thus the 3,274 fatal accidents, 37,302

Table 5. International Comparative Road Traffic Accident rates. (Denominator is number of registered vehicles)(Greece 1991 data) ${ }^{2,3,4,5,}(d=b / a \quad e=c / a)$

\begin{tabular}{llllll}
\hline & $\begin{array}{l}\text { No of } \\
\text { registered } \\
\text { vehicles (a) }\end{array}$ & $\begin{array}{l}\text { No of } \\
\text { Reported } \\
\text { RTA's (b) }\end{array}$ & Deaths (c) & $\begin{array}{l}\text { Ratio total } \\
\text { crashes per } \\
\text { No of } \\
\text { registered } \\
\text { vehicles (d) }\end{array}$ & $\begin{array}{l}\text { Ratio deaths } \\
\text { per No of } \\
\text { registered } \\
\text { vehicles (e) }\end{array}$ \\
\hline Greece & 2888009 & 20764 & 1790 & 0.00719 & 0.00062 \\
Cyprus & 457693 & 6640 & 128 & 0.01451 & 0.00028 \\
Great Britain & 26300000 & 232665 & 3274 & 0.00885 & 0.00012 \\
\hline
\end{tabular}

Table 6. Comparative increase in risk for Road Traffic Accidents between Cyprus and Greece and Cyprus and Great Britain 1996 (Greece 1991 data). 2,3,4,5

\begin{tabular}{lll}
\hline & $\begin{array}{l}\text { Increase in risk } \\
\text { for all crashes }\end{array}$ & $\begin{array}{l}\text { Increase in risk } \\
\text { for fatal crashes }\end{array}$ \\
\hline Cyprus/Greece & 2.02 & 0.45 \\
Cyprus/Great Britain & 1.64 & 2.25
\end{tabular}

serious accidents and 195,363 slight accidents reported reveal that in Cyprus an individual has 1.64 times the risk of having an accident than a driver in Great Britain and over twice the risk of dying as a consequence(4)(5). International comparisons of death rates by RTAs are given in Tables 5 and 6 . Motor vehicle accidents are the leading cause of death of adolescents and young adults worldwide nearly three quarters of road deaths occur in developing countries and men comprise a mean of $80 \%$ of casualties(6).

Various theories have been put forward to explain the high road traffic and death rate in Cyprus. They include the lack of periodic mandatory vehicle inspections, poor driver training including the use of safety belts, the effect of alcohol upon driving and the relatively infrequent use of crash helmets by motorcyclists. The Cypriot Republic is currently addressing some of these problems; for example a law requiring the wearing of crash helmets by motorcyclists was introduced in the autumn of 1999. Frequent mention was made in the MRS accident reports that drivers were not wearing a seatbelt and that motorcyclists were not wearing a crash helmet.

Nofal and Saeed showed that in Saudi Arabia that road traffic accidents were more common during the hot summer months(7). They noted that more accidents occurred in the early afternoon when the sunlight was the most intense. Our study shows a non-significant trend towards the summer months, however a confounding variable may be the unquantifiable increase in traffic due to the large increase in tourist traffic. It is thus not possible to state that it is a true relationship.

The United States of America reduced its death rate from 5.5 per million miles travelled in 1966 to 1.8 in 1992 by the imposition of minimum safety standards, crashworthiness improvements, seat belt laws and reduced alcohol use(8). Analysis of the statistics for the British Army reveal that Cyprus has the second highest road traffic accident rate of any Command after the Former Republic of Yugoslavia(9). Given the figures for the Cypriot Republic, this is to be expected. Within the International Comparisons of Transport Statistics 19701994 report, the United Kingdom is reported as having one of the lowest death rates from RTAs in the Western World, whereas Greece with Cyprus have some of the highest(10).

Road traffic accidents have been shown to 
affect an individual's physical and psychological health as well as affecting the relatives of the injured or dead person. In one study $49 \%$ of people involved in an RTA developed sleep problems, 55\% headaches and $41 \%$ distressing nightmares. In the bereaved relative $26 \%$ of individuals have been shown to have suicidal feelings three years after the loss of their loved one (10)(11).

The workload of the MRS in supporting an emergency ambulance service to the Eastern Sovereign Base Area is not insignificant, most especially as it is not a core activity of the Unit - this is to support and treat HM Forces personnel, their families and other entitled personnel. Whilst there are direct benefits to the military staff in terms of keeping skilled in the management and treatment of seriously ill patients which would have direct relevance on military operations there are potential disadvantages in terms of the number of staff required to be available out of hours. The necessity to reassess and re-train staff on a six monthly cycle for basic and advanced life support is fully accepted given the high probability that the skills will be needed frequently.

\section{Conclusion}

Overall, given the high number in Cyprus as a whole it is not surprising that nearly $45 \%$ of emergency call outs were for RTA's. Of all call outs, $53 \%$ of patients assessed and treated were not members of the British Forces community and over three quarters of all patients were seen with trauma of a greater or lesser extent. Measures to reduce the high risk of having a RTA are being adopted by the Republic of Cyprus. Individuals need to take the necessary precautions, such as wearing a seatbelt or a crash helmet, that have been shown to reduce both the morbidity and mortality in other parts of the world.

The views expressed in this article are wholly those of the authors. They may not represent those held by the Ministry of Defence.

The authors would like to thank Major Lesley Wright for reviewing the earlier drafts of this paper and providing constructive advice.

\section{References}

1. Department of the Environment, Transport and the Regions. Road Accident Statistics 1996; UK Government Statistical Service

2. Cyprus Department of Statistics and Research Transport figures. 1996

3. Kadara M and Kondakis X. Road Traffic accidents in Greece: Recent trends 1981-1991. European Fournal of Epidemiology 1997; 13: 765-770

4. Department of the Environment Transport and the Regions. Recent Statistics 1997; UK Government Statistical Service

5. Department of the Environment Transport and the Regions Highways Economics Note No. 1 1996; UK Government Statistical Service

6. Odero W Garner P and Zwi A. Road traffic injuries in developing countries: a comprehensive review of epidemiological studies. Tropical Medicine and International Health 1997; 2: 5. 445-460

7. Nofal FH and Saeed AAW. Seasonal variation and weather effects on road traffic accidents in Riyadh City. Public Health 1997; 111: 51-55

8. Robertson LS. Reducting Death on the Road: The effects of minimum safety standards, publicised crash tests, seat belts and alcohol. American fournal of Public Health. 1996; 86: 31-34

9. British Army Road Safety Report 1996/97 (unpublished)

10. Transport Statistics Report. International Comparisons 1970-1994. The Department of Transport. 1994; UK Government Statistical Service

11. Impact of Road Death and Injury. European Federation of Road Traffic Victims. Jan 1997; European Commission 